\title{
Uma pernambucana decidida: Nancy Wanderley na chanchada (1954-1960) ${ }^{1}$
}

///////////////// Júlio Lobo

1. Este trabalho é dedicado à memória de Nancy Wanderley, Félix de Athayde e João Cabral de Melo Neto. Nossos agradecimentos especiais a Renato Luiz Pucci Jr.

2. Doutor em ciências da comunicação (estética do audiovisual) pela Universidade de São Paulo (2002). Coautor do livro Glauber, a conquista de um sonho (Os anos verdes). Professor adjunto da Faculdade de Comunicação da Universidade Federal da Bahia. Professor titular do Departamento de Ciências Humanas da Universidade do Estado da Bahia.E-mail: jceslobo@hotmail.com 


\section{Resumo}

Esse ensaio visa analisar de que modo a atriz carioca Nancy Wanderley construiu o tipo da pernambucana valente, principalmente com relação ao uso da força física, na maioria de suas participações na comédia cinematográfica musicada carioca, a chanchada, a partir de um estereótipo da mulher nordestina consolidado no baião Paraíba. Para isso investiga-se a origem histórica do termo, a transformação daquela canção em sucesso musical, bem como o surgimento de sua matriz audiovisual, a Madame Pau-Pereira no filme É fogo na roupa (1952). Aqui, analisaremos cinco filmes: O petróleo é nosso (1954), No mundo da lua (1958), O camelô da rua larga (1958), Quem roubou meu samba?(1959) e Samba em Brasília (1960).

Palavras-chave

Cinema brasileiro e nordestinos, cinema brasileiro e nordestinas, cinema brasileiro e estereótipos de gênero, Nancy Wanderley.

Abstract

This essay aims to examine how the carioca actress Nancy Wanderley Rio built the kind of brave Pernambuco woman, especially regarding the use of physical force, in most of its stake in carioca musical comedy film, the slapstick, from a stereotype of women Northeast consolidated in the ballad Paraíba. For that investigates the historical origins of the term, the transformation of that song in musical success as well as the audiovisual appearance of his matrix, the Madame Pau-Pereira in É fogo na roupa (1952). Here, we analyze five films: O petróleo é nosso (1954), No mundo da lua (1958), O camelô da rua larga (1958), Quem roubou meu samba? and Samba em Brasília (1960).

\section{Keywords}

Brazilian cinema and Northeastern, Brazilian cinema and Northeastern Brazilian woman, Brazilian cinema and gender stereotypes, Nancy Wanderley. 
Sou nega, nega baiana,

revolucionária das caatingas do sertão.

Sou bamba no bamboleio.

Ô, minhas comidas é entre os soldados do batalhão.

De faca pernambucana

não vejo home na minha frente.

Não vejo não!.

Nega Baiana (Ary Barroso,1930)

O Brasil, qualquer Brasil,

quando fala do Nordeste,

fala da peixeira, chave

de sua sede e de sua febre.

As facas pernambucanas, João Cabral de Melo Neto

\section{Introdução}

A comédia cinematográfica musicada carioca, pejorativamente denominada de chanchada, que teve o seu ciclo, grosso modo, consolidado entre os anos de 1949 (com Carnaval no fogo) e 1962 (com Mulheres e espiões), é marcada, com relação à composição de suas principais personagens, pela fixação de vários tipos, advindos do teatro de revista, principalmente do circo, da literatura, da música 
popular e até do próprio cinema. Considerando-se como tipo aquela personagem plana, de identificação fácil e reconhecimento imediato, ele busca sintetizar certas determinantes profissionais, psicológicas, culturais, econômicas etc. Muito da eficácia do tipo depende do fato de ele ser considerado uma personagem préconstruída e previsível, considerando-se o contexto sociocultural que envolve a produção artística.

Trabalharemos neste texto com a conceituação de tipo tal como se encontra sintetizada pioneiramente pelo teórico da literatura Georg Lukács (1973), ao considerá-lo como uma subcategoria da personagem. Para ele, o tipo pode ser entendido como uma "personagem-síntese entre o individual e o coletivo, entre o concreto e o abstrato", tendo em vista o intuito de "ilustrar de uma forma representativa certas dominantes do universo diegético em que se desenrola a ação, em conexão estreita com o mundo real com que estabelece uma relação de índole mimética". Além disso, o tipo, segundo o caráter e a situação, é "uma síntese original, que reúne organicamente o universal e o particular. $\mathrm{O}$ tipo não o é graças ao seu caráter médio. Pelo contrário, ele se torna tipo porque nele convergem e reencontram-se todos os elementos determinantes, humana e socialmente essenciais, de um período histórico".

Do ponto de vista das determinantes profissionais, ocupacionais ou econômicas, os tipos nesse ciclo do cinema brasileiro foram amplos, privilegiando-se várias minorias: barbeiro, carteiro, motorista de lotação, afinador de piano, vendedor ambulante, sambista, barnabé, servente, político, ladrão, empresário teatral escroque etc. Uma vez que há minorias sociais, também há aquelas personagens que simbolizam um certo status: médicos, políticos, cientistas, artistas da cultura erudita etc. Do ponto de vista psicológico e sociocultural, mais próximo ao que vai ser desenvolvido ao longo desse texto, podemos elencar uma outra tipologia dessas personagens planas, as quais podem também ser simplificadamente arroladas pelo princípio do gênero. Nesse aspecto, os tipos masculinos mais frequentes são o malandro, o Don Juan, o mocinho, o vilão, o palhaço, o deputado baiano e o recruta biruta, entre outros. 
Os tipos femininos mais presentes na comédia cinematográfica musicada carioca são a mocinha (interpretada por Eliane Macedo, Adelaide Chiozzo, Inalda de Carvalho ou Dóris Monteiro), a melhor amiga da mocinha (Adelaide Chizzo), a megera (Suzy Kirby ou Violeta Ferraz), a paraíba (inicialmente por Violeta Ferraz, mas também por Sônia Mamede e Consuelo Leandro), a enérgica dona de pensão (Maria Vida, Rosa Sandrini e Zezé Macedo), a solteirona (Zezé Macedo, quase que exclusivamente), e a escroque ou malandrinha (Dercy Gonçalves), entre outros. Essas composições acompanhavam muito o que se tinha no teatro de revista carioca da época, nos programas humorísticos das rádios Nacional e Mayrink Veiga e na música popular brasileira de todos os tempos.

Está, entre esses tipos acima, aquele que será trabalhado neste texto: a mulher nordestina destemida, desaforada e, principalmente, valente, atributo esse associado à violência física. Esse tipo, denominado na gíria carioca de paraíba, marcou, em nosso entendimento, a carreira da atriz carioca Nancy Wanderley (Stelita de Souza, 1927-2008). Ela foi a valente pernambucana em seis dos oito filmes dela a que tivemos acesso, de um total de 11 . Consideramos essa frequência relevante para a generalização em torno desse tipo a que empreenderemos a seguir.

Assim como a existência do tipo mocinho, com a sua mocinha respectiva, pressupõe a existência de um vilão, a ocorrência de uma paraíba também pressupõe um tipo que, ao contrastála fortemente, a evidencie. Na comédia musicada carioca, a mocinha, em geral, é analisada com uma feminilidade que se traduziria muito simplificadamente por esses atributos: juventude, alegria, ingenuidade, candura, prestimosidade, amorosidade, beleza, doçura, fragilidade, seriedade, recato, meiguice e com um comportamento exemplar, o que significava que ela impedia “os avanços dos rapazes" (VIEIRA, 1990; DIAS, 1993; BASTOS, 2001). Além dessas características, essa mocinha era obrigada a “repetir alguns dos atributos indispensáveis aos 'heróis' e aos ‘bons”, contanto que ela ainda respeitasse os "limites impostos pelo recato necessário a esses filmes, assistidos por toda a família” (VIEIRA, 
1990, p. 162). Tem sido notado também que a composição dessa mocinha incorpora alguns traços das protagonistas dos romances populares femininos dos anos 1950 com, pelo menos, uma diferença: "a mocinha das chanchadas será a expressão da ambiguidade das personagens femininas, pois estarão inseridas no universo público: trabalharão fora, serão atrizes, cantoras, funcionárias públicas etc" (DIAS, 1993, p. 91).

Essas caracterizações acima sobre a mocinha da chanchada podem vir a ser consideradas justamente aquilo que Simone de Beauvoir (1980, p. 21, p. 73), já em 1949, apontava como signos de uma passividade, que seria um componente essencial da mulher feminina: "[Esse] é um traço que se desenvolve nela desde os primeiros anos, mas é um erro pretender que se trata de um dado biológico. Na verdade, é um destino, que lhe é imposto por seus educadores e pela sociedade". E mais: "Ser feminina é mostrarse impotente, fútil, passiva, dócil. A jovem deverá não somente enfeitar-se, arranjar-se, mas, ainda, reprimir sua espontaneidade e substituir, a esta, a graça e o encanto estudados, que lhes ensinam as mais velhas" e, consequentemente, "toda afirmação de si própria diminui sua feminilidade e suas probabilidades de sedução".

As considerações de Beauvoir com relação à feminilidade, culturalmente falando, de certa forma, atualizam no pós-guerra europeu algumas das ideias defendidas pelo filósofo e parlamentar inglês John S. Mill (2000, p. 39-40), muitas décadas atrás, mais propriamente em 1869: "O que atualmente é conhecido como natureza feminina é uma coisa eminentemente artificial - resultado da opressão forçada em algumas direções - e apresentada como não natural em outras". Ele politiza prontamente essa representação ao argumentar que "sem hesitação, nenhuma outra classe de pessoas dependentes teve seu caráter tão distorcido de suas proporções naturais através da relação com seus senhores. As noções formadas sobre a natureza feminina são ridículas, meras generalizações empíricas, sobre os primeiros exemplares apresentados". E conclui ele: "A ideia popular sobre tal natureza [feminina] é diferente em diferentes países, de acordo com as opiniões e circunstâncias sociais que o país ofereceu para as mulheres que lá vivem". 
A escolha nossa pela montagem de um corpus de filmes para uma discussão em torno de estereotipias de identidades culturais de nordestinas, de certa forma, dados os devidos descontos, retoma uma proposta de Siegfried Kracauer (1988, p. 17) especialmente na monografia De Caligari a Hitler. Nela, ele então generalizara a propósito de certo período do cinema alemão de ficção, partindo de uma premissa de que os filmes refletem a "mentalidade de uma nação" de um modo mais direto do que qualquer outra mídia por dois motivos: "primeiro, os filmes nunca são produto de um indivíduo; [...] já que qualquer unidade de produção cinematográfica engloba uma mistura de interesses e inclinações heterogêneas". Assim, segundo ele, "o trabalho de equipe nesse campo tende a excluir o tratamento arbitrário do material do cinema, suprimindo particularidades individuais em favor de traços comuns a muitas pessoas" (KRACAUER, 1988). Argumenta ainda Kracauer que filmes "são destinados, e interessam às multidões anônimas. Filmes populares - ou para sermos mais precisos, temas de filmes populares - são supostamente feitos para satisfazerem os desejos das massas" (KRACAUER, 1988). E conclui: "O que os filmes refletem não são tanto os credos explícitos, mas dispositivos psicológicos - essas camadas profundas da mentalidade coletiva que se situam mais ou menos abaixo da dimensão da consciência" (KRACAUER, 1988, p. 18).

Mais perto de nós no tempo, o historiador cultural inglês Peter Burke (2004, p. 20) vem defendendo respostas positivas para a seguinte questão: em que medida e através de quais formas as imagens oferecem evidência confiável do passado? Argumentando certa longevidade da percepção do filme, bem como da fotografia imóvel, como fontes históricas, a sua digressão se expande também em direção a narrativas cinematográficas de ficção em que nota um "valor heurístico", proporcionado por determinados filmes, inclusive aqueles de ficção, pois eles poderiam veicular "sem discurso explícito", "uma posição crítica em relação às teses correntemente defendidas e às fontes a partir das quais a História se faz" (BURKE, 2004, p. 25). O pensamento de Burke, nesse aspecto, tem certa proximidade com a postura que os historiadores culturais adotaram, a partir da influência francesa dos Annalles, quando começaram a 
se interessar pelo Outro/Outra. Interesse que acabou por buscar na Psicologia Social as contribuições das análises de estereótipos, entre outras coisas. Sobre a estereotipia, diz Burke: "Quando ocorrem encontros entre culturas, é provável que a imagem que cada cultura possui da outra seja estereotipada" e o estereótipo pode não ser "completamente falso, mas, frequentemente, exagera alguns traços da realidade e omite outros" (BURKE, 2004, p. 153; p. 155).

Ao associarmos, aqui, mundo histórico e representação ficcional, temos em mente também as posições de Ferro (1996, p. 202-203), estimuladas pela sua pertinente questão: "De que realidade o cinema é verdadeiramente a imagem?" Indagação-programa de pesquisa, que se segue de premissas:

a) resta estudar o filme, associá-lo ao mundo que o produz porque o filme, imagem ou não da realidade, documento ou ficção, intriga autêntica ou pura invenção, é História;

b) o filme abordado não como uma obra de arte, porém como um produto, uma imagem-objeto, cujas significações não são somente cinematográficas. Ele vale por aquilo que testemunha; e

c) a crítica não se limita somente ao filme, integra-o no mundo que o rodeia e com o qual se comunica necessariamente.

\section{Matrizes de um estereótipo}

Para um melhor entendimento da aposta que fazemos aqui, tornase necessário traçar breves contornos do contexto em que surge o tipo paraíba, o que nos remeterá a um certo passado que começa a se delinear pelas campanhas eleitorais para presidente da República em 1930. Entre outros objetivos, essa memória busca articular uma mitologia criada em torno de um Estado da Federação, a partir de um hino para um herói morto, que tem parte de sua ideia central retomada em um jingle para outra campanha presidencial, agora em 1950. Essa peça publicitária vira uma canção, lançada comercialmente por Emilinha Borba, com o título de Paraíba 
e se torna um dos maiores sucessos de sua carreira e dos seus compositores: Humberto Teixeira e Luís Gonzaga. Como se não bastasse tanta intertextualidade, esse baião serve como um leitmotiv para uma sequência da comédia Aviso aos navegantes (também de 1950), criando o tipo cinematográfico paraíba, que marcaria a carreira de Nancy Wanderley, entre outras atrizes brasileiras.

O paulista Júlio Prestes concorria com o gaúcho Getúlio Vargas, da Aliança Liberal (com João Pessoa, governador da Paraíba, como vice) pela Presidência da República em 1930. A morte do paraibano, episódio decisivo para o deslanchar da Revolução de 1930, também foi alvo de uma peça musical cívica, o Hino a João Pessoa (E. Souto e O. Santiago, 1930), que se inicia localizando o protagonista regionalmente, sinalizando para a metáfora do político como uma iluminação:

\footnotetext{
Lá do Norte um herói altaneiro, que, da Pátria, o amor conquistou foi um vivo farol que, ligeiro, acendeu e depois se apagou.
}

Em seguida, o dado regionalizante estadual sai da cartografia e vai para a geografia regional:

\author{
João Pessoa, João Pessoa, \\ bravo filho do sertão. \\ toda a Pátria espera um dia \\ a tua ressurreição.
}

Após essa celebração, vem o dado de política de gênero - expressão ainda não formalizada àquela época: 
vive ainda, vive ainda

no coração do Brasil.

A sinalização para o citado dado de gênero está na palavra “varonil", por sinal, muita usada em hinos pelo fato de rimar com Brasil. Mas varonil não é sinônimo de cidadão, por exemplo, mas, sim, um sinônimo para viril. O Hino a João Pessoa se encerra com a estrofe, que diz mais respeito ao título desse ensaio, e que começa por um oxímoro:

\footnotetext{
Paraíba, ó rincão pequenino,

como grande esse homem te fez.

Hoje em ti cabe todo o destino,

todo orgulho de nossa altivez.
}

O contraste criado pelo confronto das dimensões territoriais daquele Estado $\left(56.372 \mathrm{~km}^{2}\right)$ com o seu peso na eclosão daquela revolução acabou por transformar, na cultura popular, o "rincão pequenino" na Paraíba pequenina. Talvez essa tenha sido a segunda vez em que se pôde notar deslizamentos de sentidos em torno desse topônimo. O nome em pauta vem do tupi-guarani, pa'ra (rio) a’iba (ruim); a ruindade aqui estava relacionada à dificuldade de navegação na maioria de seu trecho. O nome do rio passou a ser o da capitania. Com a vitória da Revolução de 1930, João Pessoa sai dos hinos fúnebres em direção à glória post-mortem com uma marchinha que estende o seu culto a todo um Estado:

\footnotetext{
De sul a norte, todos viram a intrepidez

de um Brasil heroico e forte

a raiar no dia três.

A Paraíba, terra santa, terra boa

finalmente está vingada.

Salve o grande João Pessoa.
} 
O fato é que a memória do assassinato de João Pessoa e o papel da Paraíba na eclosão da Revolução de 1930 voltam à tona, 20 anos depois, associando política e música popular brasileira no baião Paraíba (Luiz Gonzaga e Humberto Teixeira). A sua primeira estrofe poderia estar tranquilamente em qualquer canção de retirante, das muitas que o Rei do Baião compôs ou interpretou:

\author{
Quando a lama virou pedra \\ e mandacaru secou \\ quando arribação, de sede, \\ bateu asa e voou \\ foi aí que eu vim-me embora \\ carregando a minha dor.
}

Esse canto de dor se encerra nominando a destinatária daquela mensagem: "Hoje, eu mando um abraço pra ti, Pequenina". Após esse endereçamento particular, vem o refrão famoso, retornando às lutas contra e a favor dos candidatos da Aliança Liberal em 1930:

\author{
Paraíba, masculina \\ muié macho, sim, sinhô. \\ Eita, pau-pereira \\ que em Princesa já roncou. \\ Eita, Paraíba, \\ mulher-macho, sim sinhô! \\ Eita, pau-pereira, \\ meu bodoque não quebrou.
}

Pau-pereira era uma referência ao coronel José Pereira, chefe político de Princesa que em 28 de fevereiro de 1930 se rebelara contra a decisão do governador João Pessoa de desarmar chefes políticos que, como ele, possuíam guarnições de jagunços. 
Foi tudo muito rápido: de uma hora para outra, a qualificação de resistência civil de um Estado nordestino passou a ser estendida estereotipadamente para um dado comportamental de mulheres, dado esse que não se coadunava com o que o senso comum, e talvez nem só ele, entende como sendo a cartilha da feminilidade. Estado resistente, Estado viril, mulher masculinizada, paraíba. A já famosa canção acima começou a ser veiculada como um jingle de campanha, encomendado pela Casa Civil do presidente Eurico Dutra para promover a candidatura de José Américo de Almeida a governador da Paraíba em 1950. O curioso no jingle acima é que ele celebra justamente aquele que fora derrotado por José Américo, enquanto secretário do Interior e Justiça do então presidente da Paraíba (não se usava ainda o termo governador), numa empreitada que quase custara a vida de Américo. Graças a essa e outras ações, ele fora nomeado interventor federal com a vitória da Revolução de 1930 e chefe do Governo Central do Norte até a posse de Vargas.

Como dissemos, o famoso refrão celebrava a resistência da cidade de Princesa às tropas do governador Álvaro Carvalho. Essa reação está civilmente incorporada à vida cultural da Paraíba desde a criação de sua bandeira. Em forma retangular, ela apresenta a expressão "nego", em caixa alta, com letras brancas sobre fundo vermelho e preto, sendo que essas estão inscritas na parte vermelha. A parte negra representa o luto pelo assassinato de João Pessoa, e a cor vermelha possui dois sentidos: ela representa o sangue derramado pelo citado líder e a cor de sua campanha no Partido Liberal. "Nego" foi a expressão de rebeldia que João Pessoa pronunciara quando não quis aceitar a candidatura do paulista Júlio Prestes à Presidência da República.

Inicialmente, o famoso refrão foi considerado pela oposição como um insulto à mulher paraibana, criando-se um tumulto quando o então jingle foi cantado em comício de José Américo em maio de 1950. Independente de toda essa polêmica regional, a carioca Emilinha Borba lançou esse baião com enorme sucesso nacional ainda em 1950. Àquela época, a RCA Victor, empresa transnacional com a qual o sertanejo Gonzaga tinha contrato exclusivo, não permitia que ele gravasse cantando sob o argumento 
de um dos diretores de que ele tinha "voz de sovaco". Uma prova audiovisual do sucesso mencionado acima é que, ainda em 1950, a canção podia ser utilizada apenas em sua versão instrumental e, ainda assim, conseguir transmitir a mensagem estereotipada de seu refrão. Aconteceu aqui o que muitos almejam conseguir nas narrativas audiovisuais massivas em qualquer época: ter um tema instrumental associado à entrada em cena de determinada personagem, o que se chama de leitmotiv. Trata-se de uma palavra alemã, que significa motivo condutor, sendo associada em música a uma breve fórmula musical (melódica, harmônica, rítmica), que pode ser facilmente percebida em sua repetição.

\section{Uma matriz audiovisual}

O leitmotiv que nos interessa está associado à mulher-paraíba e, curiosamente, em uma comédia musicada carioca na qual não há personagens nordestinas, quanto mais paraibanas: Aviso aos navegantes (Watson Macedo, 1950). Cleia (interpretada por Eliana Macedo) é uma cantora que está voltando ao Brasil após uma temporada em Buenos Aires em um transatlântico que tem como imediato o seu namorado (Anselmo Duarte). Motivado por uma suspeita infundada de que ela o estaria traindo, ele resolve se aproximar de uma passageira, que o assediava acintosamente. Há um baile no navio, a personagem interpretada por Eliana se embriaga em seu camarote em companhia de um clandestino (Oscarito). Ambos resolvem ir para a festa. Eliana lá chega fumando um charuto e dança animadamente um baião orquestral com esse homem. Em determinado momento, Cleia decide soltar baforadas na cara da rival enquanto esta dançava com o imediato. A moça bate em Eliana, que se abaixa e revida com um tabefe. Sem motivo aparente, outras mulheres começam a trocar tapas. O maestro (Bené Nunes), de costas para o salão, tem a sua atenção chamada pelo barulho dos tapas e pelo quebra-quebra. Ele, então, para a orquestra e diz algo baixinho para os músicos. Começa-se, então, a ouvir a canção Paraíba, apenas em versão instrumental. As lutas entre as mulheres prosseguem, o maestro mostra-se animado com o inusitado, e o clandestino aproveita a confusão para fugir do 
baile. Cessada a briga, Adelaide (A. Chiozzo) diz para Cleia que ela "acabou com o baile" ao que esta responde com orgulho: "Eu apanhei, mas dei tanta bofetada”.

Da matriz da paraíba, interpretada rapidamente por Eliana, em Aviso aos navegantes, para a confecção do protótipo audiovisual bastaram apenas dois anos. Assim como a passagem de Paraíba de jingle de campanha eleitoral para sucesso, inicialmente, de Emilinha Borba, foi um pulo, o mesmo aconteceu com a consequente estereotipagem da mulher daquele Estado. Defendemos que seria difícil termos, no cinema brasileiro de ficção, uma paraíba se ela não tivesse sido antes um sucesso musical, um jingle de campanha política e, anterior a isso tudo, uma ideia presente na cultura política, associando-se mulher viril a um Estado subitamente masculinizado. Repetindo: não é à toa que a versão instrumental do baião Paraíba é executada como música de fundo para a briga entre as mulheres no filme Aviso aos navegantes.

O fato é que em 1952 uma comédia musicada carioca faria desse tipo que estava sendo criado a personagem principal daquele que talvez seja o primeiro filme protofeminista brasileiro, o É fogo na roupa (Watson Macedo, 1952).Trata-se também da primeira comédia musicada brasileira em que temos uma personagem nordestina como protagonista e, o que é excepcional, não se trata de uma imigrante, nem tem origem rural: a paraibana Madame Pau-pereira (Violeta Ferraz). A trama principal desse filme gira em torno de um tema nada regional ou mesmo nacional: a eterna guerra dos sexos. Essa batalha está centralizada na realização de um impensável, pelo menos àquela época, Primeiro congresso das esposas em defesa da fidelidade conjugal, presidido por Madame.

A caracterização regional e caricata da protagonista de $E ́$ fogo na roupa (título que se refere a uma gíria carioca da época equivalente a complicado) dá-se logo em sua aparição em uma das primeiras sequências, quando o mestre de cerimônias do hotel a apresenta publicamente como presidente do congresso. Ela surge em cena vestida de paletó e gravata, saia, cabelos amarrados para cima quase escondidos por uma boina, fumando um charuto e com gestos grosseiros, configurando o estereótipo fácil de homossexual 
feminina em comédias - configuração de orientação sexual ou, mais amplamente, de gênero que, na gíria carioca da época, denominava-se paraíba. Essa expressão posteriormente passou a ser estendida na cidade do Rio de Janeiro para todo e qualquer imigrante nortista ou nordestino de qualquer sexo e de origem humilde e que tem validade discriminatória até os dias de hoje. O próprio nome dela, Madame Pau-pereira, já sinaliza para a origem histórica da expressão na canção Paraíba (Luiz Gonzaga e Humberto Teixeira), principalmente nesses versos: "Paraíba masculina/muié-macho, sim sinhô!".

O fato da protagonista de É fogo na roupa, Madame Pau-pereira, ser caracterizada desde a sua primeira aparição como uma paraíba, em 1952, era a finalização de um processo de estereotipagem. Como parte dele, tivemos vários tipos de matrizes: a matriz, digamos, histórica, com o Hino a João Pessoa; os deslizamentos semânticos que se produziram a partir da ideia de um Estado resistente, um Estado viril, que masculiniza a sua mulher; uma matriz musical, a partir de um jingle de campanha política que vira sucesso popular com Emilinha Borba e, posteriormente tem sua melodia associada à figura de uma mulher que troca socos em Aviso aos navegantes. O segundo passo nesse processo de estereotipagem é a duplicação em que o traço destacado, via hino e baião, deslocado do contexto que o gerou - a Revolução de 1930 - começa a ser produzido em série. No nosso caso específico, podemos localizar facilmente os contextos em que vários termos foram cristalizados com determinadas significações pontuais, mas que, por força da estereotipagem, essas significações acabaram por ser reapropriadas na realidade imediata - com um tipo de duplicação distorcida - com finalidades discriminatórias, muito mais do que de identificação cultural prestigiada. A parte final do processo de estereotipagem comumente é constituída pela generalização: toda mulher nordestina fisicamente valente é uma paraíba.

Mais acima, ao nos referirmos ao surgimento do baião-jingle Paraíba, mencionamos a política de gênero. Há mais dela nesse texto, referindo-se mais propriamente à orientação que se pretende na análise que se segue: os estudos de gênero, hoje substituindo aqueles 
chamados estudos sobre a mulher. Para a historiadora Joan Scott (1992), o termo gênero ganha em seu conteúdo social e relacional das antigas distinções baseadas em sexo, como "estudos da mulher", pois o gênero, como consequência de diferenças percebidas, inclui quatro elementos inter-relacionados. São eles os símbolos culturais, os conceitos normativos, as organizações e instituições e a identidade subjetiva. Aqui, nessa discussão, os símbolos culturais naturalmente serão destacados. A ponte entre a canção Paraíba e a discussão que se propõe dos papéis de Nancy Wanderley como uma paraíba - uma nordestina valente - tem um forte débito com as teorias feministas do cinema, principalmente aquela relativa a aspectos de uma “identidade" feminina (CASETTI, 1995, p. 204-219). Nesse ângulo, há uma tentativa de se recusar definições essencialistas tais como o eterno feminino - e procurar trabalhar a identidade cultural como um construto cultural, em particular como o produto de uma série de discursos que circulam na sociedade. Essa postura pode ser rapidamente simplificada nos seguintes tópicos: o que dizemos sobre as mulheres, o modo como falamos com elas e o que faz serem o que são.

\section{Enfim, a protagonista: Nancy}

A atriz carioca Nancy Wanderley começou a sua carreira de coadjuvante (fez, no total, 11 filmes) na comédia musicada carioca com a criação de um tipo regional, a pernambucana valente - em $\mathrm{O}$ petróleo é nosso (Watson Macedo, 1954) —, ao qual estaria associada até os seus últimos trabalhos nas telas: uma tradução audiovisual do estereótipo da Paraíba masculina, termo popularizado pela canção de Gonzaga e Humberto Teixeira. A caracterização da personagem em pauta busca ficar mais próxima daquelas proporcionadas pelo baião-jingle, por certa literatura regionalista nordestina (Luziahomem, 1902, de Domingos Olímpio, por exemplo) e pelos programas radiofônicos e televisivos de humor da época - e de sempre. Nesse sentido, proliferam expressões ditas pela dama no filme, tais como avexada, vixe, enxerido, sem-vergonho. Tem-se ainda com ela um uso bastante peculiar da sintaxe e do léxico da língua portuguesa, como em puliça (polícia) e vorta (volta). 
Além de tudo isso apontado acima, a dama associa a sua naturalidade (pernambucana) a um traço de personalidade: a valentia. Aqui está pontualmente a estereotipia da identidade cultural regional. Um exemplo bem claro do que se aponta aqui é quando ela toma conhecimento por meio de uma foto de matéria de manchete do diário carioca O Globo - "Petróleo à flor da terra" - que o seu gigolô estava posando de geólogo francês e hospedado no Hotel Glória. Ela então vocifera: "Indivíduo inescrupuloso. Vai me pagar. Ele vai ver quanto vale uma pernambucana”. Ato contínuo, ela sugere atos de violência física contra o citado. Antes dessa promessa, ela já o provocara, chamando-o de "enxerido" e "sujeito baixo", e dizendo-lhe que ele só era valente para mulheres.

A comédia No mundo da lua (Roberto Farias, 1958) é o quarto filme de Nancy Wanderley no qual ela é a única mulher (chamada Nancy) de uma quadrilha de trapalhões chefiada por um estrangeiro sem nacionalidade identificada ou presumível (Frederico Schlee), que sequestra Matias (Walter D’Ávila), um industrial carioca mulherengo e preguiçoso, para forçá-lo a revelar para eles a fórmula da produção de um tipo de cimento que estaria fazendo sucesso no mundo todo. A gangue consegue localizar um sósia desse empresário e o coloca na direção da empresa para que ele aja segundo o interesse do grupo de criminosos. Aqui, se destaca o recurso dramático do duplo que, por sinal, é antigo nas artes narrativas, funcionando como um veículo para a ambientação de crises de identidade pessoal. Nas abordagens mais tensas, essas crises são instantes preparatórios para desfechos trágicos em que, geralmente, a personagem duplicada comete um crime pelo qual a personagem original deve pagar. Independente de exemplos de tragicidade, o duplo tem alimentado, principalmente nos filmes, incontáveis comédias cujos argumentos invariavelmente usam e abusam da troca de identidade entre sósias.

O clone do empresário, Zé da Foice (o mesmo D’Ávila), é um pequeno produtor rural e locador de terras no Rio Grande do Norte, Estado que ele nomeia como sendo "o fim do norte", e que viera ao Rio de Janeiro apenas para conhecer pessoalmente a sua noiva por correspondência, Dolores del Mar (Violeta Ferraz), 
a quem ele chama de Dora, cujo compromisso fora iniciado em páginas de consulta sentimental de uma revista. Ele se faz acompanhar na viagem e na cidade por um tocador de zabumba, Mário (Reginaldo Faria).

Os dois companheiros de viagem são logo involuntariamente separados quando chegam ao Rio de Janeiro a partir do momento em que Zé da Foice acaba sendo envolvido com outro nordestino por causa de um doente mental, que o acusa de roubar as sandálias que ele estava vendendo. Em função da denúncia do vendedor de sandálias, Zé da Foice é levado à prisão, de onde é libertado mediante o pagamento de uma fiança, o que é feito por Nancy, que já observara o agricultor em sua chegada ao Rio. Libertado o potiguar, ele é convencido pelo bando do estrangeiro, mediante um bom pagamento, a fazer o papel do empresário por apenas um dia, tempo suficiente para que eles obtenham duas coisas: o acesso a um cofre na empresa, onde estariam depositados 30 milhões de cruzeiros (valores da época), e o segredo da fórmula de um produto de sucesso internacional: o "famoso cimento brasileiro". Zé da Foice aceita fazer o papel, mas fica contrariado por ter sido proibido de entrar em contato com Dora.

Enquanto isso, o verdadeiro empresário, dopado por uma mulher, fica fora de cena, à beira de uma piscina e sem se dar conta de mais nada. Mais adiante, ele é internado em um manicômio, enquanto estava desacordado. Ninguém lamenta a ausência de Matias. A esposa vivia apoquentando-o, pedindo-lhe desquite, o que o clone prontamente concede; a secretária dele apenas estranha que o clone tenha tanta vontade de trabalhar, o que não era uma virtude do original.

Apesar de ter sido considerado pela personagem Nancy como um "matuto muito bronco", “idiota”, Zé da Foice surpreende a todos em seu primeiro dia de trabalho pela desenvoltura com que lida com um norte-americano que retornara procurando Matias para a compra de suas terras. Zé da Foice dialoga fluentemente em inglês com o visitante. Quando este lhe pergunta onde aprendera a falar esse idioma, ele diz que havia trabalhado com soldados norte-americanos numa base de Natal durante a Segunda Guerra 
Mundial. Ou seja, esse caipira é singular: proprietário de terras no Nordeste, não fala de seca, nem de fome, não critica os governos e viaja ao Rio de Janeiro apenas por questões sentimentais.

O fato é que desde o momento em que Nancy é vista no desembarque dos nordestinos, viajantes potiguares, para sermos mais precisos, ela mostra traços de valentia, de dureza mesmo, na linha de composição do tipo que ela usara como uma prostituta pernambucana na Lapa do já citado filme O petróleo é nosso (1954). A sua personagem tem uma função estratégica no bando, mas suas falas buscam realçar uma propensão à grossura e a uma proposta de truculência física, como se percebe nesses trechos de diálogos: "Guarde essa valentia, aí, ô, palhaço!" (para um comparsa) e "Não grita comigo, não, ô, careca, senão vai acabar conhecendo o gostinho do chumbo quente" (para o violento chefe da quadrilha). Em outro momento, a vilã pernambucana defende a tortura do empresário sequestrado: "Mas não há ninguém que saiba onde ele [Zé da Foice, sósia do empresário] está, senão, a gente torturava até ele falar". Um pouco mais adiante, ela sugere que, tão logo a quadrilha tenha acesso à chave do cofre, o industrial seja assassinado. Nesse filme, como em muitos outros, Nancy continua sendo vilã e caracterizada como pernambucana, mas em nenhum dos outros ela surge como sequestradora ou torturadora.

Para acentuar o que a personagem de Nancy entende por nordestinidade, ela também profere para o empresário as expressões que o gênio Luiz Gonzaga tornara famosas nacionalmente: cabra da peste e cabra da muléstia. O primeiro desses qualificativos é o título de um baião, de Gonzaga e Zé Dantas, lançado em1955, que começa assim:

Eita!, sertão do Nordeste, terra de caba da peste.

Só sertanejo arriseste anos de seca e verão. Toda dureza do chão faz também duro o homem que vive no sertão. 
$\mathrm{Na}$ estrofe seguinte, a canção trabalha com polaridades, mas continua celebrando uma determinada virtude:

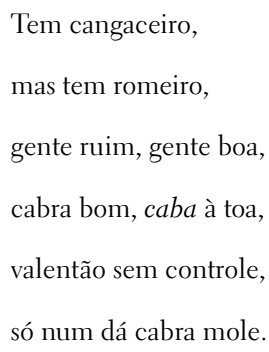

A valentona sem controle nesse filme é, tranquilamente, Nancy. Por outro lado, a menção que a caipira faz à morte por peixeira aqui retoma outra que fora feita ao que seria um traço de nordestinos cabras da peste logo na sequência da prisão do agricultor. Naquela ocasião, o médico havia alertado Zé para o fato de que o vendedor de sandálias já havia matado quatro pessoas.

Há um dado curioso na composição da personagem interpretada por Nancy nesse filme. Ele diz respeito à parte policial da trama. É que ela, não tendo nenhum pudor nacionalista, participa de uma quadrilha que quer vender para o exterior uma patente nacional, mas se preocupa com uma nordestinidade. Tão logo ela libera o agricultor da cadeia, ela critica o fato de ele, um nortisto, não ter sotaque nordestino - como se sabe, Walter D’Ávila era gaúcho. Mas talvez não se deva levar muito a sério essa nordestinidade, pois ela busca um sotaque acariocado e gírias respectivas quando responde a um alerta do comandante de sua quadrilha: "Chefe, já morei no lance!" O fato da gângster criticar uma falta de sotaque nortisto no fazendeiro potiguar traz à cena uma situação curiosa: a de alguém se importar mais com traços de uma identidade cultural regional, mais propriamente nortista/nordestina, do que com um sentimento de pertencimento a um Estado-nação: o Brasil. Como se sabe, ela é membro de uma quadrilha que está comercializando uma patente nacional para o estrangeiro.

Muito simplificadamente, respeitando-se as variedades estaduais, uma das marcas mais notadas desse modo de falar 
o brasileiro, o nortisto, mencionado pela gângster, o sotaque nordestino, é a abertura nas vogais - o por ó, e por é, i por iii (especialmente na Paraíba). Nas áreas influenciadas por escravos que falavam o banto, e como nesse idioma não há palavras com duas consoantes juntas, tende-se a se pronunciar peneu, no lugar de pneu, ou adevogado, em vez de advogado. Sobre o sotaque da dita pernambucana, ela falha, por exemplo, em não pronunciar butar, marca pernambucana supraclasse, no lugar de bôtar (como os sulistas) ou bótar, como os baianos. Ainda a propósito do nortisto, há quem veja em ocorrências desse tipo uma postura política de alguns cineastas do ciclo no sentido de assimilarem, readaptarem e disseminarem o discurso populista dominante: "Não surpreende, pois, que louvações triunfalistas à ignorância e ao desrespeito à prosódia correta, sobretudo através das personagens interpretadas por Golias e Nancy Wanderley, tenham proliferado com tanto vigor naquele período" (AUGUSTO, 2005, p. 174-75).

Analisando-se detidamente esse filme em outros aspectos, podemos notar pontualmente um grande movimento em extrair uma comicidade de gargalhada através da estereotipia - para não dizer do preconceito mesmo. Discutiremos a seguir algumas dessas cenas para fundamentar a nossa observação. Zé da Foice, apesar do apelido, não é um roceiro ou boia-fria. Ele é um pequeno proprietário rural e, em determinado momento, anuncia claramente que vivia da renda de terras no "Norte". Sendo assim, não se justifica dramaticamente que ele se desloque do Rio Grande do Norte para o Rio de Janeiro em um caminhão pau-de-arara, quando poderia fazê-lo, via terrestre, através da rodovia Rio-Bahia, disponível desde 1939... Poderia ter vindo também, devido às suas alegadas posses, por um daqueles navios da Companhia Ita, cantados na belíssima canção com que Caymmi celebrava uma imigração: Peguei um Ita no norte. As terras no norte servem ainda como uma alegoria mal trabalhada sobre a presença de estrangeiros na Amazônia quando, em uma sequência logo no início, um norte-americano oferece ao verdadeiro Matias uma grande quantia pelo seu latifúndio naquela região, o que ele recusa. 
Ao final, toda a gangue é presa, e o matuto potiguar finalmente pode se encontrar com a sua amada por correspondência.

\title{
Um baiano decidido: Zé Trindade
}

Em O camelô da rua larga (Euripides Ramos, 1958), Nancy Wanderley interpreta Aurora, uma auxiliar de camarim de uma boate e eterna noiva da personagem-título Vicente (Zé Trindade). Para o ponto que nos interessa mais aqui, relativo à destemida pernambucana, a sequência mais específica se dá no local de trabalho da noiva: uma boate. Vicente está saindo do local em que Aurora trabalha quando ambos esbarram com os capangas do namorado da vedete da casa. Forma-se logo uma pequena confusão. O camelô arremeda um discurso de valentia, enunciando-a juntamente com a sua naturalidade: "Num baiano decidido, ninguém bota a mão. Vai tudo virar mungunzá". O que se segue é ele fugindo à luta. Enquanto ele arrota valentia, ela, discreta, é quem é valente. A expressão "baiano decidido" lembra-nos uma canção de Baiano, Baiano dengoso, gravada em 1907, principalmente na sua primeira estrofe:

\author{
Sou baiano, \\ sou cabra dengoso, \\ sou baiano de todos querido, \\ sou baiano, sou forte e dengoso, \\ sou baiano, sou bem decidido.
}

Tem-se, então, no caso do filme acima citado, um ato curioso: a autoidentificação não vem associada a uma positividade, mas, sim, relacionada com uma inversão, a qual aponta para uma covardia. É claro que a composição da personagem-título não comporta apenas covardia, uma vez que, para trabalhar, ele precisa desafiar a lei, o que demanda algumas virtudes.

Um daqueles capangas citados, Ladainha, é rude com a costureira, que não se intimida e diz desaforadamente para ele: "Não fica folgando com a gente, não, porque senão vai sobrar coco 
nesse coqueiro”. Vicente tenta interceder, temendo uma represália de Ladainha, mas ela é dura também com o eterno noivo: "Sai pra lá, moloide! Deixa que eu me acerto com eles!” Ato contínuo, Aurora avança aos tapas e bofetões para cima de Ladainha e de outro capanga. Quando o primeiro vacila um pouco, ela lhe aplica um belo soco. Na confusão, o camelô pega uma mala no chão, pensando que era a sua, mas se tratava de outra, cheia de muamba, guardada pelo dono da boate, com dinheiro falsificado.

No entanto, nesse filme, excepcionalmente, não é apenas a personagem interpretada por Nancy que tem um perfil de valentia. Sem qualquer identificação de uma origem regional - o que acontece invariavelmente com atores nordestinos nas chanchadas —, Dona Bebé (Maria Vidal) é uma pessoa agressiva, rude até, e capaz de brigar fisicamente com qualquer um, pois pratica boxe, o que é anunciado visivelmente pelo par de luvas apropriadas que mantém penduradas na sala de estar na sua pensão à vista de todos. Esse dado foi considerado tão importante pelos produtores do filme, que ela é parte de destaque no cartaz justamente numa pose de briga.

O perfil de uma valente pernambucana que Nancy Wanderley construiu para a maior parte de seus papéis no cinema carioca mostra-se desde o início em sua relação com o noivo, bem como com meliantes. Com a personagem-título (Zé Trindade) de $\mathrm{O}$ camelô da rua larga, ela é bastante atenta às tentativas de assédio dele às coristas do seu emprego e não se acanha de, quando é preciso, agredi-lo fisicamente... com beliscões nas nádegas. No entanto, ela sabe que não conseguirá nem à força fazer com que o seu noivo com ela se case ou que, pelo menos, arranje o que ela considera um emprego "decente". A sua premência pelo casamento faz com que ela tenha até que ferir a sua autoestima na verbalização de sua ânsia. Isso pode ser notado quando ela diz: "Eu já estou ficando bastante castigada, ficando pra titia. Eu estou ficando que nem mamão maduro. Se você não me tirar logo do pé, a passarada começa logo a beliscar”. Aqui temos, mais uma vez, essa associação tão frequente na cultura brasileira entre sexo e comida, possibilitada principalmente pela polissemia do verbo comer. Possidônia (Zezé Macedo), a cozinheira da pensão, também sofre discriminações 
por ser uma mulher de meia-idade e ainda solteira, sendo chamada pelas próprias vizinhas, por sua condição, de "fósforo apagado". O desabafo dela estimula duas digressões: uma relativa à associação comida-sexo e outra com respeito às questões de gênero e cultura no Brasil e fora dele.

A associação grosseira feita à eterna noiva do camelô tem, infelizmente, respaldo na cultura brasileira, para o que aponta o antropólogo Roberto da Matta (1991, p. 60), tratando de outro objeto, a partir das seguintes premissas: a) "as comidas se associam à sexualidade de tal modo que o ato sexual pode ser traduzido como um ato de 'comer', abarcar, englobar, ingerir ou circunscrever totalmente aquilo que é (ou foi) comido"; b) "a comida, para a mulher (ou o homem em certas situações), desaparece dentro do comedor - ou do comilão”. A partir desses aspectos, ele argumenta que essa é a "base da metáfora para o sexo", sinalizando que "o comido é totalmente abraçado pelo comedor". Em sua síntese, esse antropólogo afirma que a relação sexual e o ato de comer, dessa forma, estão tão intimamente relacionados que os brasileiros conceberiam a sexualidade e a veriam "não como um encontro de opostos e iguais (o homem e a mulher que seriam indivíduos donos de si mesmos), mas como um modo de resolver essa igualdade pela absorção, simbolicamente consentida em termos sociais, de um pelo outro". Por sinal, em quase todos os filmes que Zé Trindade protagonizou abundam piadas explorando essa associação.

A expressão ficando pra titia talvez seja a menos amarga para se referir a uma mulher que, tendo ultrapassado determinada faixa de idade, não se casou. As outras expressões eram bastante duras: "mulher que não tem marido", mulheres que "torceram a natureza", que "viraram facão" e que são megeras, amargas, invejosas, inúteis, frustradas. Trata-se de um preconceito, que não é exclusivamente brasileiro, transformado em motivo para riso nas falas de algumas personagens de Nancy Wanderley, bem como, principalmente, na maioria dos papéis de Zezé Macedo. A historiadora Cláudia Maia (2008, p. 46-51), ao analisar aspectos da conjugalidade moderna associada ao terror moral no Brasil entre 1890 e 1948, coloca vários aspectos em torno desse tópico em sua associação com a solteirona, 
ressaltando o fato de que muitas mulheres permaneciam solteiras devido à migração masculina, às guerras e aos altos custos do matrimônio, pois havia, em algumas regiões, o instituto do dote. Em plena vigência dos desejados modelos de mãe-esposa-dona-decasa, observa essa pesquisadora, as solteironas eram "um elemento desestabilizador, pois não só recusavam os papéis destinados a elas, mas transitavam livremente pelos espaços de trabalho, governando suas vidas e seus próprios bens. Por isso, elas eram retratadas como indesejáveis".

\section{Baiana? Vírgula!}

Em 1940, o compositor baiano Assis Valente resolveu aproveitar a realização de um censo nacional para criar um samba em que glosava com aquele levantamento oficial: Recenseamento. A narração é de uma mulher (a canção fora feita especialmente para Carmen Miranda), que atentamente vai respondendo às questões do agente sobre estado civil, ocupação do companheiro etc., ao tempo em que faz crítica social e aponta para signos do lazer de ambos. Do cenário do barraco, a narradora passa para uma descrição do que o país significava para ela:

\footnotetext{
Fiquei pensando e comecei a descrever tudo, tudo de valor que meu Brasil me deu: um céu azul, um Pão-de-açúcar sem farelo, um pano verde-amarelo, tudo isso é meu.

Tem feriado que, pra mim, vale fortuna.

A Retirada da Laguna vale um cabedal.
}

Pelo exposto, esse episódio histórico entra mais nos versos dessa canção para compor uma rima do que para exibir uma insuspeita cultura escolar da narradora. Recenseamento se encerra com versos curiosos, pois a narrativa pula da descrição para uma proposição, que é o que mais nos interessa nesse samba: 
Tem Pernambuco, tem São Paulo e tem Bahia, um conjunto de harmonia que não tem rival.

Aparentemente, a escolha dos Estados a representarem uma utopia de harmonia suprarregional poderia ocorrer por obra de um acaso ou por questões de rima interna emparelhada (caso de Bahia/harmonia, mas que não se aplica aos outros dois Estados). No entanto, esse fecho nos interessa mais pelo mistério que cerca a sua composição do que dele se pode alegorizar. Pernambuco, São Paulo e Bahia, historicamente, estão associados por terem sido os três primeiros polos de povoamento do Brasil. Até aqui, tudo bem. Mais uma lição de História do Brasil por parte da "favelada". Mas o nosso foco é ainda mais restrito: pelo exposto pelo compositor, Pernambuco e Bahia comporiam uma "harmonia que não tem rival", o que não se confirma, pelo menos, nas representações cinematográficas de uma pernambucanidade a cargo de Nancy Wanderley. Nelas, tem-se uma vez ou outra, mesmo que rapidamente, uma vontade de distinção intrarregional, onde se poderia esperar uma generalização, tipo “é tudo a mesma coisa”.

O louvor à "harmonia sem igual" entre os dois Estados nordestinos poderia ser considerado, com certa ousadia, como uma resposta criativa a uma proposição cercada de estereotipia científica que podemos localizar pontualmente em um livro tido como clássico entre os explicadores do Brasil: Casa-grande e senzala, de 1933, do bairrista pernambucano Gilberto Freyre (1990, p. 288-289), no capítulo em que ele discorre sobre o escravo negro na vida sexual e de família do brasileiro. O discurso dele começa classificando as regionalidades por aspectos étnicos e não histórico-culturais, como se estivéssemos diante do pensamento racista do século XIX:

Contrastando-se o comportamento de populações negroides, como a baiana (alegre, expansiva, sociável, loquaz) com outras menos influenciadas pelo sangue negro e mais pelo indígena (a piauiense, a paraibana ou, mesmo, a pernambucana), tem-se a impressão de povos diversos (FREYRE, 1990, p. 288-289). 
Em seguida, não se tem ideia clara se os baianos estão sendo elogiados ou desclassificados:

Populações tristonhas, caladas, sonsas e até sorumbáticas [são] as do extremo Nordeste, principalmente nos sertões: sem a alegria comunicativa dos baianos, sem aquela sua petulância, às vezes, irritante. Mas, também, sem a sua graça, a sua espontaneidade, a sua cortesia, o seu riso bom e contagioso (FREYRE, 1990, p. 288-289).

Por fim e gratuitamente sem qualquer base empírica, o que nunca foi o forte desse senhor, vem a generalização, procedimento típico da estereotipia, do preconceito, em suma: "Na Bahia, tem-se a impressão de que todo dia é dia de festa”.

Essa parte do nosso texto busca justamente analisar de que modo a formatação das personagens pernambucanas interpretadas por Nancy Wanderley busca se distanciar de uma similaridade com representações de uma baianidade, postura traduzida no título acima, parte de um diálogo do filme Quem roubou meu samba? (J. C. Burle, 1959). No filme em pauta, seu sétimo papel de coadjuvante, Nancy Wanderley continua interpretando personagens trabalhadoras que são envolvidas afetivamente com cidadãos pouco afeitos ao batente regular, como nos filmes nos quais participou no ano anterior: $\mathrm{O}$ batedor de carteiras, em que se enamora da personagem-título (Zé Trindade), e O camelô da rua larga formando um par romântico com esse mesmo ator. Aqui, o seu namorado-problema é Leovigildo Coruja (Ankito), que se toma como empresário artístico e como sócio-proprietário de uma agência de detetives, mas que é visto mesmo em sua primeira sequência como um mascate. Nancy faz o papel de Iolanda, uma auxiliar de enfermagem do público Hospital Socorro dos Prontos, que tem o seu trabalho interrompido frequentemente pelos telefonemas e visitas fora de propósito e de hora dele. Este pensa fazer uma súbita riqueza adquirindo os direitos autorais de um samba do compositor Atanásio (Chuvisco), que já os havia vendido simultaneamente a duas gravadoras. 
Como se não fosse o suficiente ter vendido um mesmo samba para duas empresas, Atanásio o comercializa para o seu agente, que o paga com o dinheiro que consegue arrancar com a sua noiva, com quem está junto há 12 anos. Em meio a tudo isso, a única pessoa honesta e de bom senso é a auxiliar de enfermagem. Em várias oportunidades, ela chama a atenção do noivo para o fato de que as atividades dele, de detetive particular e de empresário artístico de um sambista malandro, não se constituiriam a rigor em trabalho. Na primeira sequência de ambos juntos, ela o saúda assim: "E aí, arranjou emprego?” Diante da expressão dele, conotando uma negativa, ela esbraveja: “Oxente! Dou um duro danado da moléstia... e ele fica vagabundeando. Se você quer ganhar sem fazer nada, arranje uma vaga de jacaré no jardim zoológico". O neologismo que iniciou essa última frase é o resultado da aglutinação nas expressões “Ó, gente!” ou “Ô, gente!”, significando surpresa ou estranheza.

Por sinal, raras vezes a comédia cinematográfica musicada brasileira conseguiu essa síntese de colocar dois participantes importantes de uma trama sendo suficientemente caracterizados, como personagens, logo em sua primeira sequência em conjunto. Por sinal, o tema de fundo da citada sequência é uma ilustração dramatizada de outro tema bastante rico no universo da cultura popular brasileira, notadamente em sua música correspondente: a relação gênero-trabalho. Esse contraste malandro versus mulher ordeira, despertado pelas admoestações de Iolanda a Leovigildo e ampliado em seu cotejo com alguns sambas acima, já foi brilhantemente analisado, tendo como corpus mais de uma centena de sambas, por Matos (1982, p. 174-75) com a seguinte síntese: "Tal como a união do trabalhador com a mulher malandra, a do malandro com a mulher doméstica está fadada ao insucesso. Isso explica a grande quantidade de sambas malandros, que falam da falência da união conjugal com a mulher-mãe".

Dezoito anos após a dissertação de Cláudia Matos, cujo trecho citamos acima, o antropólogo Ruben Oliven (2000, p. 104-105) desenvolve raciocínio semelhante sobre o tema em foco, tomando como corpus algumas canções produzidas entre as décadas de 1930 e 1940 em que nota que são recorrentes as queixas e acusações contra 
um perfil de mulher. Essas reclamações se referem principalmente à questão do trabalho. Ele é visto como uma "imposição feminina" ao homem e rejeitada por estar sendo entendida como a mulher, enquanto "representante do mundo da ordem, estar lembrando ao homem a necessidade de se inserir no processo produtivo" (OLIVEN, 2000, p. 104). Ou seja, “a rejeição do trabalho se dá, aqui, junto com a rejeição de valores que estariam associados a certo tipo de mulher" (OLIVEN, 2000, p. 105). A questão da relação gênero-trabalho volta à tona quando Ankito, não encontrando mais oportunidades junto à gravadora, tenta se justificar horrorosamente: "Quem trabalha para mulher é cinta ou soutien."

Mesmo após a descompostura dele pela namorada, Leovigildo prossegue seguindo-a hospital adentro, contra o regulamento, até o momento em que ela, entrando em seu setor, bate-lhe a porta na cara. Atordoado, ele se volta em direção à saída do local quando esbarra em um auxiliar do banco de sangue, testemunha do descontrole justificado de Iolanda, que lhe pergunta: "O que é que a baiana tem?" Ele, irritado: "Pimenta”. Para que se pudesse produzir alguma comicidade nessa sequência em pauta, foi necessário que o auxiliar tomasse Iolanda, na ausência dela, como uma baiana, o que, para ele, aparentemente nativo do Rio de Janeiro, poderia ser uma identidade regional a ser estendida indistintamente para nortistas/nordestinos. No entanto, mais adiante, essa atribuição retornará, e ela mostrará que isso a incomoda.

O episódio em que a pernambucana Iolanda roda a baiana dentro do hospital é a primeira vez na qual o casal de namorados é visto em cena juntos, ocasião em que o empresário tenta extorquir a sua amada, já que ele nada ganha com o seu único contratado nem com a sua empresa, a "Agência de Investigações A Eterna Vigilância” ("Tudo vê, tudo sabe, tudo informa"). No segundo encontro deles, fora do ambiente do hospital, ele, enfim, consegue arrancar 500 cruzeiros dela de quem ouve o qualificativo, entonado com raiva, de "cabra da peste". Essa expressão, pouco familiar ao universo de gírias do carioca da época, talvez tenha sido nele introduzida pelo cancioneiro mais antigo de Luiz Gonzaga, inicialmente com "Cabra da Peste" (L. Gonzaga - Zé Dantas, 1955), definindo o 
estereótipo assim: "Eita! Sertão do Nordeste/ Terra de caba da peste $[\ldots]$ /Valentão sem controle”.

Atanásio está preparando um novo samba, mas como ele não lê nem escreve música nem tampouco toca qualquer instrumento, tem apenas a sua memória para guardar a melodia. As coisas se complicam porque o compositor não entrega a sua mercadoria - uma canção - a nenhuma das gravadoras com que assinou o contrato. Tancredo (Humberto Catalano) resolve então pedir a Secundino (Aurélio Teixeira) que vá assistir a um dos ensaios da escola de samba do morro com a finalidade de obter do sambista as respectivas letra e melodia. Lá chegando, Secundino repara que Atanázio, trabalhando para dona Aurora (Maria Vidal), dona de uma gravadora, tivera ideia melhor do que a sua: com um imenso gravador, ele conseguira o registro da canção. Sem que os envolvidos o percebam, Secundino retira a fita do gravador. Ao chegar à Gravapan, ele e um auxiliar manuseiam incorretamente um gravador, apagando a fita que lá estava com a desejada obra.

A vertente policial dessa comédia se acentua no momento em que o gângster Secundino leva a fita com a cobiçada música inédita, ocasião em que se cria também um tumulto na sede da escola de samba, sendo que o preposto dá uma coronhada no compositor. Por conta disso, Atanázio é levado a um hospital. E é claro que só poderia ser o hospital em que Iolanda trabalha: Hospital Socorro dos Prontos. Lá, ele vai descobrir que se esqueceu da canção inédita como de todas as suas músicas. Isso não é de conhecimento do gângster da Gravapan, que, junto a seus capangas, invade o hospital e retira o compositor ainda adoentado, levando-o para um esconderijo. Atanázio finalmente revela o seu lado de detetive, seguindo o carro dos sequestradores. De posse desse endereço, ele entra em contato com a noiva, pedindo uma ambulância, aciona uma rádio-patrulha e convoca seus amigos de sinuca e de escola de samba na empreitada do resgate do compositor. Tendo Leovigildo à frente, o grupo entra no esconderijo.

A sequência do resgate do compositor é o momento pastelão desse filme, iniciado com Leovigildo arrombando a porta do esconderijo e em posição de ataque. Enquanto eles lutam, chega uma ambulância 
trazendo Iolanda e o auxiliar da cena "O que é que a baiana tem?", os quais, juntamente com o motorista do veículo, também entram na pancadaria, ato curioso para profissionais da saúde. Ela se sai bem em sua primeira participação: derruba um bandido que a atacara por trás. Ao constatar essa bravura e essa habilidade em lutas marciais, o citado auxiliar do banco de sangue grita entre espantado e orgulhoso para a colega: "Aí, baiana!". Descuidando- se um pouco da luta, mas atenta na defesa de uma suposta identidade cultural regional, ela lhe responde prontamente: "Baiana, vírgula! Eu sou é pernambucana". O uso da expressão "vírgula" mostra que aquela nordestina já havia incorporado, pelo menos uma gíria carioca da época, que valia por objeção, réplica, exclusão (Nascentes, 1953, p. 361). Iolanda não explica por que se irritara tanto ao ser confundida com baiana, ocasião em que se aproveita para revelar com orgulho a sua naturalidade. Curiosamente, no mesmo ano desse filme, ela manifestara semelhante reação de desagravo ao desembarcar na Estação Central do Brasil (Av. Presidente Vargas, Centro do Rio de Janeiro) quando fora abordada pelo protagonista (Zé Trindade) de O batedor de carteiras. No filme em exame, Iolanda não nos explica por que ser tida como baiana a irritara tanto.

Achando suficiente a sua participação pugilística na contenda acima resumida, Iolanda sai em socorro de Atanázio, que estava gritando para ser localizado. Essa cena é curiosa e engraçada: o compositor estava amarrado a uma cadeira, dando-nos a entender que isso faria demorar a sua libertação. No entanto, a auxiliar de enfermagem, que tínhamos acabado de ver exibindo dotes de lutas marciais, agora age como se fosse uma profissional de outros ambientes: de costas para Atanázio, ela levanta parte de seu avental até vermos um punhal enfiado na meia que reveste a sua coxa direita, lâmina essa providencial para finalizar o seu intento. Quando a pancadaria já havia se encerrado, com a dominação dos gângsteres, chegam cinco policiais munidos de vistosos cassetetes. Se a polícia não chegasse nesse momento, essa não seria uma comédia de costumes, que é o subgênero dramático da maioria e das melhores chanchadas brasileiras. 


\section{Tensão intraclasse: copa versus cozinha}

A personagem cômica da pernambucana valente com que Nancy Wanderley marcou a sua passagem pela chanchada carioca a partir de O petróleo é nosso (1954), sai de cena no filme Samba em Brasília (Watson Macedo, 1960). A atriz interpreta Albertina, uma copeira na casa de um casal de grã-finos no Rio de Janeiro que vê a sua rotina modificada um pouco com a chegada de uma nova cozinheira, a bela e versátil Teresinha (Eliana Macedo). Até então, Albertina não vira motivos para muitas preocupações com o seu auxiliar direto, o português Jiló, a antiga cozinheira e o mordomo. Às funções mencionadas correspondem as suas respectivas circulações por espaços rígida e claramente demarcados: cozinha e copa, sala de jantar, sala de visitas e quartos. A contribuição de Albertina, juntamente com a de Jiló, se dá no momento em que ela desconfiara do pessoal encarregado do bufê para a citada festa, suspeição aumentada quando eles sugerem que os garçons, velhos conhecidos da casa, sejam trocados pelos seus. As suspeitas têm uma base de ressentimento: a citada festa havia sido organizada pela ex-noiva do filho do dono casa e pela mãe dela, Beatriz. Ambas haviam tramado uma forma de desmascarar a nova noivinha, Teresa, e desmoralizar o casal de grã-finos pelo que ambas consideravam uma desfeita. A rigor, Beatriz havia empurrado a filha para o jovem pianista como um típico golpe do baú, uma vez que era uma viúva pobre e triste.

Quando a equipe do bufê tenta levar doces e salgados para o salão, a copeira pernambucana põe-se à frente de dois deles e diz acintosamente: "Por aqui não passa ninguém. Só se for por cima do meu cadáver". Quem é familiar à história da Bahia provavelmente reconhecerá na frase da valente o último brado da sóror Joana Angélica ao impedir o acesso de tropas portuguesas ao seu convento em Salvador em julho de 1823. Após a frase de cunho heroico, Albertina lembra a seus colegas que se tratava de doces estragados e que isso era uma sabotagem. Ato contínuo, a feroz pernambucana parte para as vias de fato: chuta a bandeja na mão de um dos suspeitos, dá uma gravata em outro, derruba mais um com um rolo de carne, joga torta na cara de outro e, por fim, aplica pontapés 
e murros em outro sujeito. Evidenciando uma privilegiada força física, Albertina retira, arrastando, um desses meliantes para fora da cozinha. Desse modo, os doces e salgados encomendados por ela são servidos, contribuindo para o sucesso da festa e para a citação da madame na imprensa local.

Em nosso entendimento, seria difícil termos a composição duradoura do tipo pernambucana valente, por parte da atriz carioca Nancy Wanderley, se não tivéssemos tido antes a consolidação, já explicada, do tipo paraíba, hoje incorporado à cultura popular do carioca em geral. Por outro lado, a pernambucanidade das personagens interpretadas por Nancy em algumas oportunidades se faz por contraste a outras identidades culturais regionais, como a baiana, caso pontual no filme Quem roubou meu samba? - em que não há personagens desse Estado - , e a carioca (do morro), em Samba em Brasília. As expressões relativas à naturalidade da personagem e de quem a interpreta são, como acontece na maioria dos filmes estrelados por Nancy Wanderley, sempre como uma imigrante pernambucana, veiculadas gratuitamente. Assim, o dado de identidade social não surge como contrafação a uma alteridade - com exceção do "baiana, vírgula!" - , mas, sim, como o sinal mais visível de uma esperada distinção, como se a naturalidade constituísse fonte de prestígio. Ou seja, antes de ser absorvida como mais uma migrante nordestina na antiga capital federal, essa personagem-tipo se distinguiria, entre essa minoria social, por uma pernambucanidade, dado de distinção diante de uma baianidade, de uma paraibanidade, ou de um simples nortista, como se dizia à época, em lugar de nordestino.

\section{Considerações finais}

A montagem desse breve corpus de representações típicas dos papéis de Nancy Wanderley tornou-se possível principalmente por uma característica dessa modalidade de comédia musicada, a qual pode também ser considerada como um defeito, pois nesse ciclo, os atores "não só são suportes materiais para que as personagens possam encarnar, mas significam a própria chanchada", destaca Chaia (1980, p. 70), para quem a personagem principal, cômico- 
caricatural, "é sempre a mesma nos diferentes filmes, uma vez que a sua definição, caracterização e função repetem-se de filme para filme". Por sinal, essa observação, dadas as devidas contextualizações, poderia ser feita a propósito dos papéis de John Wayne, no faroeste; de Jean Gabin, James Cagney e Humphrey Bogart, no filme de gângster; de Jerry Lewis e de Chaplin como o vagabundo etc.

Enfim, com relação à personagem interpretada por Nancy Wanderley, principalmente, bem como, em menor proporção, por Violeta Ferraz, Consuelo Leandro e Sônia Mamede, destacamos parte das considerações do historiador Durval de Albuquerque (2005, p. 34-35) em torno do "cabra da peste", o estereótipo do sertanejo machão: coronel, jagunço, cangaceiro. Em seu entendimento, o dado mais saliente nos discursos formadores da identidade nordestina é que ela é sempre pensada no masculino: "Não há lugar para o feminino no Nordeste - até a mulher é "macho, sim senhor". E mais, a mulher nordestina seria uma virago, uma mulher masculinizada por exercer tarefas masculinas nas ausências do marido, provocadas pela migração e pela seca desde os anos 1920. Já esse homem estereotipado necessita ser "forte, rústico, resistente, quase um homem-cacto, para poder resistir a um ambiente que é sempre descrito como hostil”, ao passo que as personagens femininas da chamada literatura regional usualmente ganham "contornos masculinos, já que somente uma mulher seria capaz de sobreviver em ambiente árido e violento". E mais: o homem nordestino seria assim "o último dos machos, aquele homem que ficara protegido no sertão das mudanças que a cidade anunciava" ao tempo em que é "uma figura que articula, portanto, uma identidade regional e uma identidade de gênero: ser nordestino é ser macho".

Com relação às falas destacadas de algumas das personagens marcantes de nordestinas na amostra trabalhada por nós, o historiador Durval Albuquerque (2007, p. 108-109) embora trabalhando com outro corpus, coloca um argumento, que tomamos como fecho dessas considerações, ao localizar uma matriz segura para a frequente associação entre violência e nordestinidade nas representações da temática do cangaço na literatura de cordel 
desde o final do século XIX, uma associação "eleita para representar a nordestinidade cultural, inspirando a forma de escrever de muitos autores regionalistas [e que] vai dando a este personagem uma centralidade na hora de se definir o que é nordestino". Uma das consequências dessa postura é que o nordestino, em geral, "passa a ser visto, em outras regiões, como um homem que tende à violência, como um homem disposto a puxar sua peixeira a qualquer hora e em qualquer lugar para furar a barriga do primeiro que aparecer". Nesse aspecto, talvez uma das mais importantes contribuições do cômico baiano Zé Trindade tenha sido inverter essa representação, configurando na maioria dos filmes em que contracena com Nancy Wanderley, Violeta Ferraz ou Suzy Kirky (suas megeras) aquilo que os estudos de gênero denominam hoje de masculinidade frágil.

Embora às vezes interpretada pelas mesmas atrizes (Violeta Ferraz e Nancy Wanderley, por exemplo), a megera se distingue um pouco do tipo paraíba pelos seguintes traços, assim sistematizados por Mônica Bastos (2001): a) ela é sempre feia, infeliz, dado este ressaltado plasticamente por olheiras, sulcos no rosto, rugas e envelhecimento precoce; b) além da feiura em alto grau, ela ou é muito magra (como Zezé Macedo) ou gordona (como Violeta e Suzy Kirby); c) todos os traços caminham na direção de evidenciar que a megera nunca é uma mulher desejável; e d) é uma mulher mal resolvida, marcada pela maldade, má e mesquinha. Expressão muito comum na boca das personagens de Zé Trindade, curiosamente, megera é um vocábulo com raízes na mitologia da Antiguidade Clássica: do grego mégaira, o nome de uma das três Fúrias (divindades infernais), foi latinizado como megaera, figura que era considerada como um símbolo da inveja e do ódio. Essa expressão acabou sendo popularizada no Brasil como sinônimo de mulher má e irritadiça. Da mesma forma que a protagonista da comédia shakespereana A megera domada (1594), esse tipo cômico no ciclo de filmes ora discutido comporta uma ambiguidade, que abre uma brecha para sua conversão, segundo Bastos (BASTOS, 2001, p. 82): "a megera por ser domesticada ou domada, desde que se saiba como [e] por alguém que fala mais alto ou com afeto, reforçando o conceito machista da época - para a mulher não existe problema que não se resolva com um homem". 
Por artes do destino, Nancy Wanderley encerrou sua carreira artística com um papel que remete à sua estreia nas telas $(O$ petróleo é nosso, 1954) e a outro filme seu: Quem roubou meu samba?, no qual se irrita ao ser chamado de baiana. Trata-se da telenovela Rosa Baiana (Bandeirantes, 1981), de Lauro César Muniz, com supervisão de Walter Avancini, em que ela desempenha o papeltítulo: uma mãe abnegada, que, em Salvador, ao longo de 90 capítulos, vive com os problemas de seus sete filhos e na esperança de que seu ex-marido retorne mais uma vez para casa. Os campos de petróleo da capital baiana compuseram parte dos cenários naturais numa produção patrocinada pela Petrobras.

Enfim, entre outras coisas, acreditamos que os tipos de paraíba encarnados por Nancy Wanderley, bem como por Violeta Ferraz (É fogo na roupa), Consuelo Leandro (No mundo da lua e Sai dessa, recruta!) e por Sônia Mamede (Garotas e samba), do ponto de vista da interpretação, derrubam uma tese do historiador do humor Georges Minois (2003, p. 611) de que "não há mulheres-palhaças, não há mulheres-bufas". A argumentação é de que a feminilidade excluiria o cômico e que só a "mulher velha", justamente por ter perdido a feminilidade - ele não menciona dosagem de hormônios - , poderia fazer rir. O riso entraria então em ação para suprir uma lacuna: "No jogo da sedução, o riso supre a ausência de charme. É comparável ao charme físico - aquele que ri não resiste mais".

Cremos haver ainda no discurso de Minois ecos das teorias aristotélicas sobre a comédia, especialmente no diz respeito a personagens femininas quando ele se refere aos quatro pontos que devem ser levados em conta na composição das personagens teatrais: "O segundo ponto a ser visado é a conveniência. Decerto há algo que é a coragem no caráter, mas não é conveniente a uma mulher ser corajosa ou bem dotada nesse sentido" (Aristóteles, 2011, p. 64-65). De passagem, é curioso como esse trecho parece ter sido escrito para criticar todo esse nosso trabalho. No entanto, o fulcro na teoria dele é que o cômico é relativo ao feio, ao rebaixado, que Minois poderia estar tornando equivalente à "mulher velha". O fato é que, sem sombra de dúvida, a despeito de Aristóteles, Minois e outros menos votados, todas as grandes comediantes protagonistas ou coadjuvantes dos filmes brevemente discutidos ao longo desse ensaio, são palhaças, belas palhaças. 


\section{Referências}

AUGUSTO, S. Este mundo é um pandeiro (A chanchada de Getúlio a JK). São Paulo: Duas Cidades, 2005.

BASTOS, M. Tristezas não pagam dívidas. São Paulo: Olho d’Água, 2001.

BEAUVOIR, S. O segundo sexo 2. Rio de Janeiro: Nova Fronteira, 1980.

BURKE, P. Testemunha ocular (História e imagem). Bauru, SP: Edusc, 2004.

CASETTI, F. Theories of cinema, 1945-1995. Austin: University of Texas, 1998.

DIAS, R. O mundo como chanchada. Rio de Janeiro: RelumeDumará, 1993.

FERRO, M. “O filme, uma contra-análise da sociedade?”. In LE GOFF, J.; NORA, P. (Dir.) História: novos objetos. Rio de Janeiro: Francisco Alves, 1996.

FREYRE, G. Casa-grande e senzala. Rio de Janeiro: José Olympio, 1990.

KRACAUER, S. De Caligari a Hitler. Rio de Janeiro: Jorge Zahar, 1988.

LUKÁCS, G. "Balzac et le réalisme français”. In: REIS, C.; LOPES, A. C. (Org.) Dicionário de narratologia. Coimbra: Almedina, 1994. MAIA, C. “Ó, desprezíveis solteironas!”. Revista de História da Biblioteca Nacional, Rio de Janeiro, ano 3, n. 36, p.46-51, set. 2008. MATTA, R. O que faz o brasil, Brasil? Rio de Janeiro: Rocco, 1991.

MATOS, C. Acertei no milhar (Samba e malandragem no tempo de Getúlio) Rio de Janeiro: Paz e Terra,1982.

MILL, J. S. A sujeição das mulheres. São Paulo: Escala, 2000.

MINOIS, G. História do riso e do escárnio. São Paulo: Edunesp, 2003. 
MOISÉS, M. Dicionário de termos literários. São Paulo: Cultrix, 2004.

NASCENTES, A. O linguajar carioca. Rio de Janeiro: Simões, 1953.

OLIVEN, R. G. In: LOPES, A. H. (Org.) Entre Europa e África. Rio de Janeiro: Topbooks, 2000.

SCOTT, J. "Gênero: uma categoria útil de análise histórica". Educação e Realidade, Porto Alegre, v.16, n. 2, p. 5-22, 1992.

VENEZIANO, N. O teatro de revista no Brasil: dramaturgia e convenções. Campinas: Pontes, 1991.

VIEIRA, J. L. "A chanchada e o cinema carioca”. In RAMOS, F. (Org.) História do cinema brasileiro. São Paulo: Art, 1990. 